\title{
Mechanisms controlling primary and new production in a global ecosystem model - Part II: The role of the upper ocean short-term periodic and episodic mixing events
}

\author{
E. E. Popova, A. C. Coward, G. A. Nurser, B. de Cuevas, and T. R. Anderson \\ National Oceanographic Centre, Southampton, UK
}

Received: 12 June 2006 - Published in Ocean Sci. Discuss.: 31 July 2006

Revised: 26 October 2006 - Accepted: 22 November 2006 - Published: 6 December 2006

\begin{abstract}
The use of $6 \mathrm{~h}$, daily, weekly and monthly atmospheric forcing resulted in dramatically different predictions of plankton productivity in a global 3-D coupled physicalbiogeochemical model.

Resolving the diurnal cycle of atmospheric variability by use of $6 \mathrm{~h}$ forcing, and hence also diurnal variability in UML depth, produced the largest difference, reducing predicted global primary and new production by $25 \%$ and $10 \%$ respectively relative to that predicted with daily and weekly forcing. This decrease varied regionally, being a 30\% reduction in equatorial areas primarily because of increased light limitation resulting from deepening of the mixed layer overnight as well as enhanced storm activity, and $25 \%$ at moderate and high latitudes primarily due to increased grazing pressure resulting from late winter stratification events. Mini-blooms of phytoplankton and zooplankton occur in the model during these events, leading to zooplankton populations being sufficiently well developed to suppress the progress of phytoplankton blooms. A $10 \%$ increase in primary production was predicted in the peripheries of the oligotrophic gyres due to increased storm-induced nutrient supply end enhanced winter production during the short term stratification events that are resolved in the run forced by $6 \mathrm{~h}$ meteorological fields.
\end{abstract}

By resolving the diurnal cycle, model performance was significantly improved with respect to several common problems: underestimated primary production in the oligotrophic gyres; overestimated primary production in the Southern Ocean; overestimated magnitude of the spring bloom in the subarctic Pacific Ocean, and overestimated primary production in equatorial areas. The result of using $6 \mathrm{~h}$ forcing on predicted ecosystem dynamics was profound, the effects persisting far beyond the hourly timescale, and having major

Correspondence to: E. E. Popova

(ekp@noc.soton.ac.uk) consequences for predicted global and new production on an annual basis.

\section{Introduction}

Episodic and periodic variability in the upper mixed layer (UML) of the ocean, over a range of time scales, has potentially important consequences for plankton dynamics. However, while the effect of the seasonal signal in upper ocean mixing on biology is understood comparatively well, the impact of short-term variability, on diurnal to weekly time scales, remains enigmatic. This variability includes processes like storm-induced mixing, the diurnal cycle of the UML and short periods of stabilisation of stratification during winter convection due to occasional calm weather. These processes affect nutrient supply, limitation of plankton productivity by light and the coupling between phytoplankton, herbivorous zooplankton and higher trophic levels. The potential importance of short-term periodic and episodic events for seasonal or annual plankton productivity has been debated in recent years both by observationalists (Dickey et al., 2001; Karl et al., 2001) and modellers (McCreary et al., 2001; Follows and Dutkiewicz, 2002; Waniek, 2003; Kawamiya and Oschlies, 2004). Although time series observations indicate significant responses of ecosystems to such events (e.g. Conte et al., 2003), the data coverage in terms of frequency of measurements makes it difficult to conclude whether this variability is important as regards properties such as primary production integrated over longer time periods.

Most contemporary basin-scale and global model simulations are run using slowly varying monthly climatological forcing (Palmer and Totterdell, 2001) or with simplistic UML schemes that are unable to capture short-term variability in the UML (Aumont et al., 2003). Realising the

Published by Copernicus GmbH on behalf of the European Geosciences Union. 
potential shortcomings of these approaches when it comes to modelling marine ecosystems, Kawamiya and Oschlies (2004) undertook a set of numerical experiments comparing monthly and daily averaged external forcing of a model for the Arabian Sea. Their results indicated that whereas the inclusion of high frequency forcing led to an improved representation of observed short term variability in chlorophyll, this variability was not important in predicting integrated production over seasonal and annual time scales. Primary production was suggested instead to depend mainly on total upwelling, which in turn depends only on averaged winds. In contrast, the 1-D modelling study of Waniek (2003) of plankton dynamics in the northeast Atlantic demonstrated the potential importance of the frequency and intensity of atmospheric synoptic events in affecting both variability of the UML and in turn the dynamics of the marine ecosystem. Variability in the timing and intensity of the spring bloom mediated by changes in the upper ocean mixing impacted on the population dynamics of higher trophic levels, the effect persisting beyond the bloom period.

Here, we use a 3-D General Circulation Model (GCM), with an embedded NPZDA (Nitrate, Phytoplankton, Zooplankton Detritus, Ammonium) ecosystem model, described in detail in accompanying paper (Popova et al., 2006, hereafter abbreviated to PC06), to investigate the impact of variability in short-term upper ocean mixing on predicted ecosystem dynamics and global estimates of the primary and new production. The physical model, operating at $1^{\circ}$ resolution, includes an advanced representation of UML dynamics based on the KPP (K profile parameterization) vertical mixing scheme (Large et al., 1997) of the upper ocean. Predictions for the global ecosystem are compared for atmospheric forcing on 6-hourly, daily, weekly and monthly time scales. In contrast to the findings of Kawamiya and Oschlies (2004), results show a dramatic impact of short-term variability in UML dynamics on predicted global primary and new production.

\section{Methodology}

A detailed description of the 3-D coupled physical and biological model used in this study is given in the accompanied paper (PC06). It consists of a simple ecosystem model based on the approach of Fasham et al. (1990) and Fasham and Evans (1995), although without a representation of bacteria and dissolved organic matter. The biological model state variables are phytoplankton $(\mathrm{P})$, zooplankton $(\mathrm{Z})$, detritus (D), nitrate (N), ammonium (A) and chlorophyll-a (Chl).

The biological model is coupled with the $1^{\circ}$ physical model (Ocean Circulation and Climate Advanced Modelling project, OCCAM). OCCAM uses the " $\mathrm{K}$ profile parameterization" (KPP) vertical mixing scheme (Large et al., 1997) allowing an advanced representation of water column mixing. The most significant difference between the KPP scheme and bulk models is that the UML does not need to be well mixed. KPP produces a realistic exchange of properties between the mixed layer and the thermocline. Another feature of KPP that is especially important for biological applications is the ability to handle successfully not only the annual cycle of the UML but also events of the order of only a day in duration. The KPP model has been shown to simulate many such events very well, including convective boundary layer deepening, diurnal cycling, storm induced deepening (Large et al., 1997) and short-term spring shoaling of the UML layer (see PC06).

The physical model was spun up for 8 years. This consisted of a 4 year "robust diagnostic" integration (relaxation of tracer values towards climatological values at all depths) followed by a repeated 4 year period with only surface forcing. The biological model was coupled to the physics at the end of this procedure, corresponding to the beginning of 1989. The model was then integrated, in fully coupled mode with the evolving physical fields, over a 4-year period using $6 \mathrm{~h}$, daily, weekly and monthly forcing fields. The first three years were considered as a settling period and the last year (1992) was used for the analysis. The run with $6 \mathrm{~h}$ forcing described in detail in PC06, serving as a best estimate of system behaviour by which other experiments with the daily, weekly and monthly forcing are judged.

When using $6 \mathrm{~h}$ forcing, input fields of wind speed, air temperature, specific humidity, sea level pressure, cloudiness, precipitation and short wave radiation are used in combination with the model top level potential temperature to compute the wind stress, heat and freshwater forcing to be applied at each time step. The bulk layer formulae used are the same set used in the NCAR CSM Ocean Model (NCAR/TN-423+STR). To provide comparative runs, differing only in the variability of the applied fluxes, it is not sufficient to average the input atmospheric fields over the relevant periods. Such an approach would lead to different net fluxes due to the role of the model SST field in the calculation. Instead, to produce daily, weekly and monthly forcing fields, the following approach was used:

i. The control run with $6 \mathrm{~h}$ forcing was performed and the daily average fields of all the fluxes as applied to the ocean were saved.

ii. The daily average fields were further combined into weekly or monthly averages as required.

iii. The surface forcing module of the model was adapted to read and apply the average fluxes at the required period. Note that in the calculation of the primary production in all runs, the diurnal cycle was imposed upon the incoming shortwave flux by taking into account the angle of the sun above the horizon at each timestep and location. This was done in such a way as to ensure the net daily amount was maintained. 
a)

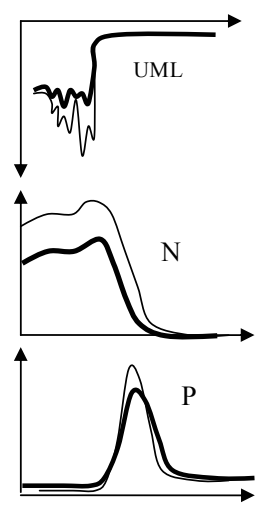

Time (winter/spring) b)

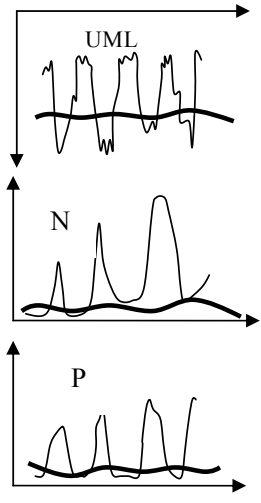

Time(summer) c)

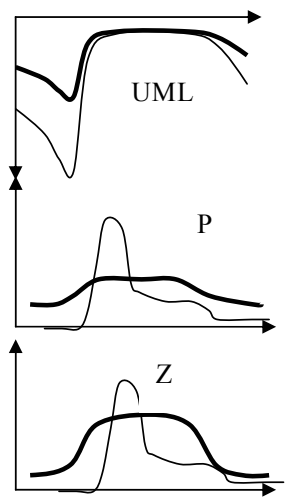

Time (annual scale)

d)
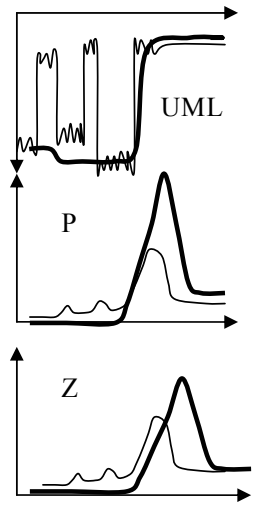

Time (end of winter)

e)

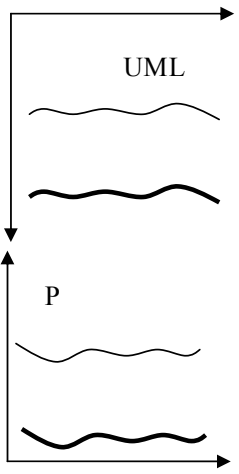

Time(summer)

Fig. 1. Schematic representation of the main UML control mechanisms over ecosystem dynamics: (a) Impact of depth of winter mixing (the major factor determining nutrient supply to the UML). Thick line describes a shallower (compared with the thin line) winter convection leading to lower nitrate concentration in the UML at the beginning of the spring, and a lower phytoplankton bloom terminated earlier by nutrient limitation. (b) Impact of short-term storm-induced summer deepening of the UML (enhances nutrient supply into the photic zone and primary production if it is nutrient-limited as opposed to light-limited). Thin line describes frequent deepenings of the UML as opposed to the stable depth (thick line) leading to the pulses of nutrients entrained from below the UML leading to an increase in phytoplankton biomass. (c) Impact of average winter mixing depth (influences the extent to which zooplankton can survive through the winter and hence exert grazing pressure on the spring phytoplankton bloom). The thin line describes a deeper (compared with the thick line) winter convection when primary production is low during the winter because of strong light limitation, leading to low zooplankton biomass which does not then put a significant grazing pressure on the spring phytoplankton bloom. In the case described by the thin line, zooplankton grazing suppresses the spring bloom. (d) Impact of short-term restratification of the UML during late winter and spring due to extremely calm weather followed by the return of deep mixing (such periods reduce light limitation and increase the level of coupling between phytoplankton and their grazers and change the dynamics of the spring bloom). Thin line describes a convective regime with a frequent near-surface restratification allowing significant production to occur, followed by the growth of zooplankton. At the moment of the spring bloom zooplankton population is then large enough to exert a significant grazing pressure on the phytoplankton. In the case of stable deep convection (thick line), the zooplankton population at the moment of the bloom is low and the first stage of the bloom develops without grazing pressure. (e) Impact of average summer mixed layer depth (determines light limitation of phytoplankton growth over the season). The thick line describes deeper (compared with the thin line) UML depth leading to higher light limitation of primary production and lower phytoplankton biomass.

\section{Results}

\subsection{UML dynamics}

The features of UML variability, on a range of timescales from diurnal to seasonal, which have the greatest influence on ecosystem dynamics through supply of nutrients, light limitation and the impact of grazing are the following (presented schematically in Fig. 1):

i) The maximum penetration of deep winter mixing (the major factor determining nutrient supply to the UML);

ii) Frequency and maximum depth of short-term storminduced summer deepening of the UML (enhances 

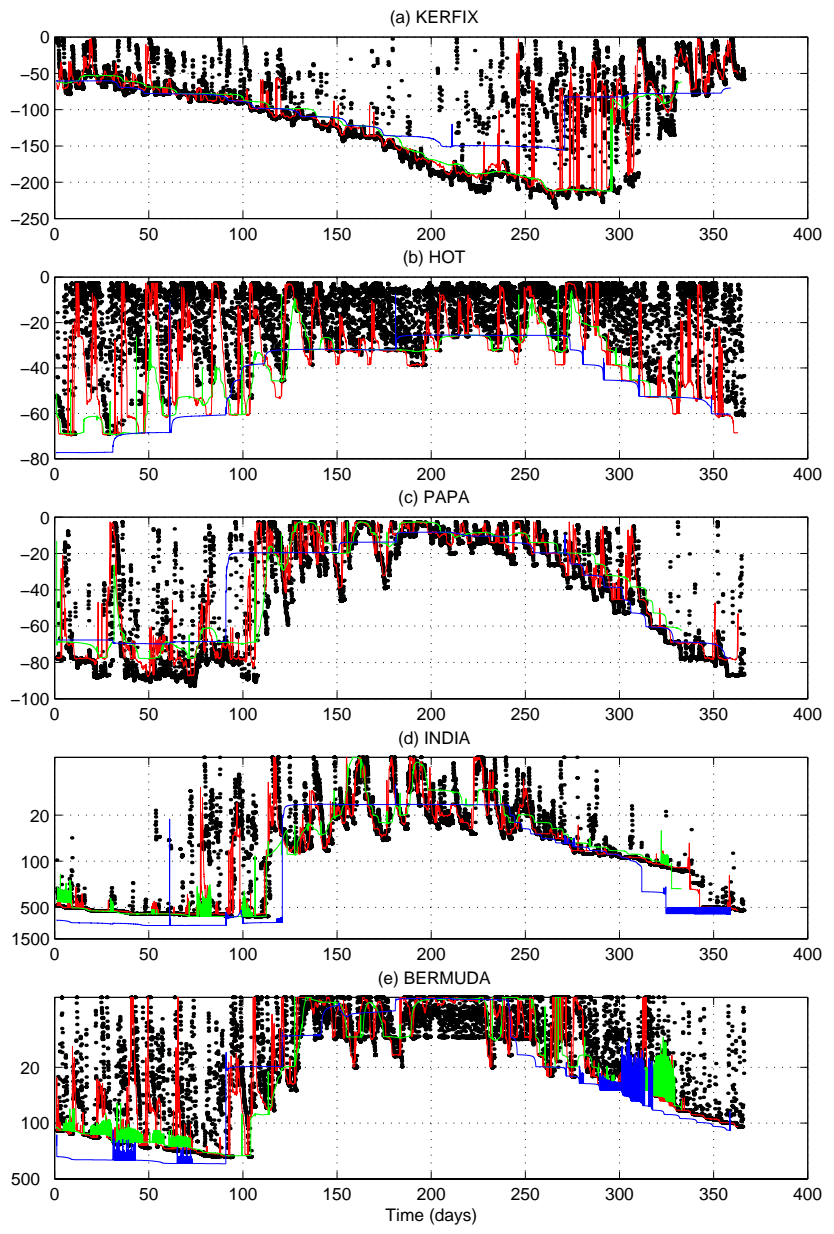

Fig. 2. UML depth variability for the year 1992 at KERFIX (a), HOT (b), Papa (c), India (d), BATS (e) in the control run (black dots), daily (red), weekly (green) and monthly (blue) forcing runs.

nutrient supply into the photic zone and primary production if it is nutrient-limited as opposed to light-limited);

iii) Average winter mixing depth (influences the extent to which zooplankton can survive through the winter and hence exert grazing pressure on the spring phytoplankton bloom);

iv) Frequency and duration of short-term restratification of the UML during late winter and spring due to extremely calm weather followed by the return of deep mixing (such periods reduce light limitation and increase the level of coupling between phytoplankton and their grazers and change the dynamics of the spring bloom);

v) Average summer mixed layer depth (determines light limitation of phytoplankton growth over the season).

In our analysis of the UML variability under the external forcing of the different frequencies, we focus on the particular mechanisms described above. Note that the UML depth (a) Contr.Run.: min monthly UML

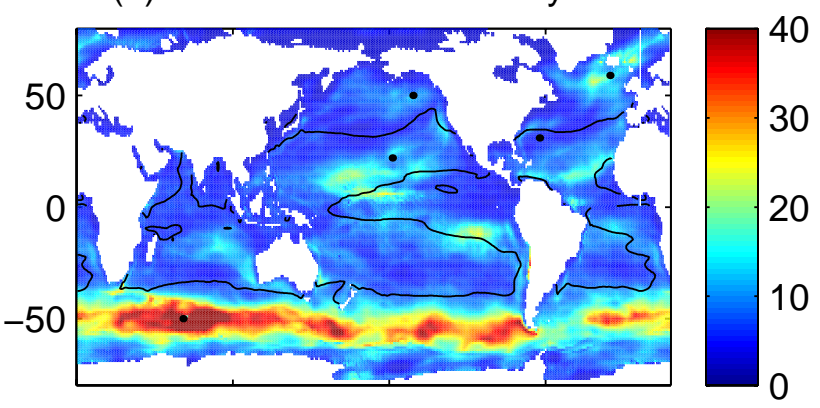

(b) Contr.R.: UMLmax-UMLmean

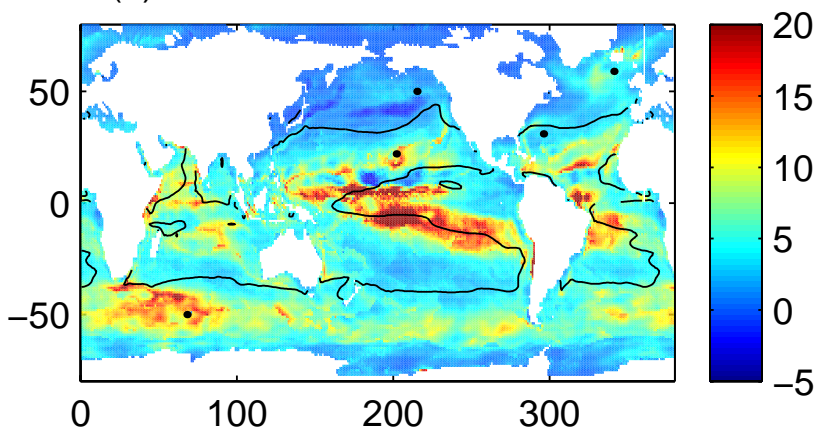

Fig. 3. (a) The monthly-averaged UML depth from the control run for the month when it is at its minimum, in m. (b) Difference (in $\mathrm{m}$ ) between the minimum monthly averaged daily maximum (nighttime) UML depth and the minimum monthly-averaged UML depth. Black dots show the locations of the five time series stations discussed in the text and shown on Figs. 2 and 10. Black line represents a mean annual nitrate concentration of $1 \mathrm{mmol} \mathrm{m}^{-3}$ also shown in Figs. 4, 7, 9, and chosen as a means of defining the boundaries between different regions described in the text.

is defined here as the depth of the actively mixing layer. This may be deeper than the depth over which density is uniform - the mixed layer - during periods of active mixing, and considerably shallower than the mixed layer e.g. during the daytime where there is a strong diurnal cycle (see e.g. Brainerd and Gregg, 1996).

The annual cycle of UML depth as predicted by the model at five JGOFS locations (PC06) for monthly, weekly, daily and $6 \mathrm{~h}$ external forcing is shown in Fig. 2. The diurnal cycle of UML depth is resolved with $6 \mathrm{~h}$ forcing, showing a characteristic shallowing during the day and deepening during the night, a feature not captured with the other forcings.

The monthly-averaged UML depth from the control run is shown in Fig. 3a for the month when it is at its minimum. This minimum monthly UML depth is a convenient proxy for the summer-time average UML depth, and therefore the influence of light limitation during the growing season (mechanism v). It is independent of hemisphere, the existence of seasonal regimes such as monsoons, and the weak annual signal seen in equatorial areas. The deepest such minimum 
UML depths are found over the Southern Ocean $(\sim 40 \mathrm{~m})$ and over the belts of strongest trade winds centred at $15^{\circ} \mathrm{N} / \mathrm{S}$ ( $\sim 20 \mathrm{~m})$.

The monthly averaged night-time UML depth gives a better idea of the depth of the mixed layer. It is deeper than the average UML depth by up to $20 \mathrm{~m}$ (Fig. 3b). These depths differ most over the trade wind belts of strong insolation and strong winds (see also the seasonal cycle at HOT, Fig. 2b), and over the Antarctic Circumpolar Current (KERFIX, Fig. 2a), where, although insolation is weaker, the night-time UML is deepest so that any diurnal restratification reduces the mean UML depth significantly.

In the trade wind belts (see Fig. $4 \mathrm{a}-\mathrm{c}$ and station HOT, Fig. 2b), the UML depth driven by the averaged forcings is similar to the night-time UML depths driven by the control forcing. Here the wind is relatively steady, so the windenergy available to drive mixing is not reduced much using the averaged forcings rather than the 6-hourly forcing. In the mid-latitudes and equatorial ocean, however, the variability of the wind on short timescales is significant relative to the mean winds. Hence there is more wind-energy in the control run to drive mixing, and so the night-time control UML is deeper than that of the averaged runs (see station Papa Fig. 2c, the North Pacific in Fig. 4a-c, INDIA - Fig. 2d, the North Atlantic in Fig. 4a-c).

At Bermuda (Fig. 2e) the extra summer mixing in the control run is very marked. Here summer insolation is strong and the winds weak, and it seems that the mixed- layer model is unable to drive any significant mixing with averaged, even daily-averaged forcing. It may only permit mixing with weak winds where there are periods of buoyancy loss (i.e. by including the diurnal cycle).

When comparing the mean UML depth from the control run against the UML depth from the averaged forcing runs (Fig. 5a-c), there are then two opposing effects. Since the daily mean UML is shallower than the night-time UML depth (see again Fig. 3b), the daily mean UML depth is shallower than the averaged forcing UML depths in regions like the trade wind belts (e.g. HOT, Fig. 2b) where the nighttime UML depth was similar to the UML depths with averaged forcing. From a biological perspective, the similarity in night-time UML depth means that nutrient supply to the system remains unaltered (mechanisms i and ii). Limitation by light should however be significantly less in the $6 \mathrm{~h}$ run compared to the other forcings because of the shallowing of the UML during the day (mechanism v). But where the extra wind energy of the $6 \mathrm{~h}$ dataset is more important in giving deeper UMLs than this diurnal averaging effect, the control mean UMLs are deeper than the averaged forcing UMLs. This behaviour is seen at Papa, India and BATS (Fig. 2c, d, e). In these areas the $6 \mathrm{~h}$ forcing gives rise to the highest vertical flux of nutrients in the model, but is accompanied by the highest levels of light limitation.

The maximum penetration of deep winter mixing determines a major part of the nutrient supply to the upper layer (a) Contr maxUML-daily meanUML

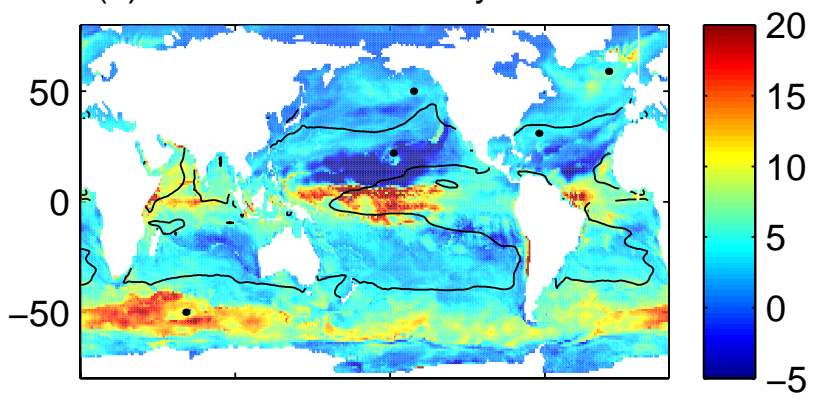

(b) Contr maxUML-Weekly mean UML

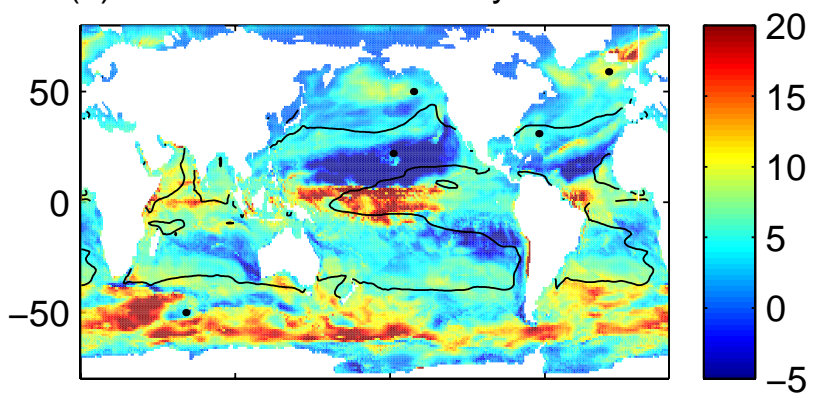

(c) Contr maxUML-Monthly mean UML

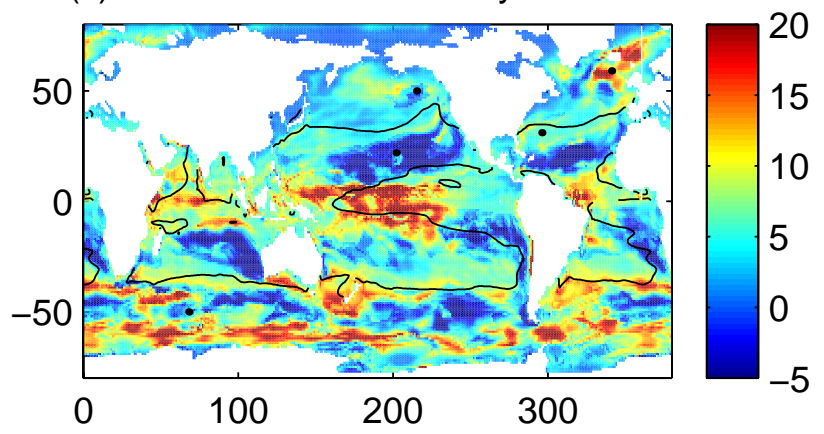

Fig. 4. Difference (in $\mathrm{m}$ ) between the minimum monthly averaged daily maximum (night-time) UML depth in the control run and the minimum monthly-averaged UML depth in the runs driven by daily averaged (a), weekly averaged (b) and monthly averaged (c) forcing.

(mechanism i). It is plotted in Fig. 6a as the maximum monthly averaged daily maximum UML depth for the control run. This depth is largely set by accumulated buoyancy loss over the winter, and so is generally similar in the $6 \mathrm{~h}$, daily and weekly runs. However the use of monthly forcing fields does substantially increase the maximum penetration of winter mixing in some areas (Fig. 2). The deviation of the maximum over the year of the monthly-mean UML depth in the monthly run from that in the control run is shown in Fig. 6b. The northern boundaries of the northern subtropical gyres and areas of deep winter convection in the northern North Atlantic experience the largest difference. Winter mixing in 
(a) Control-Daily (UML min)

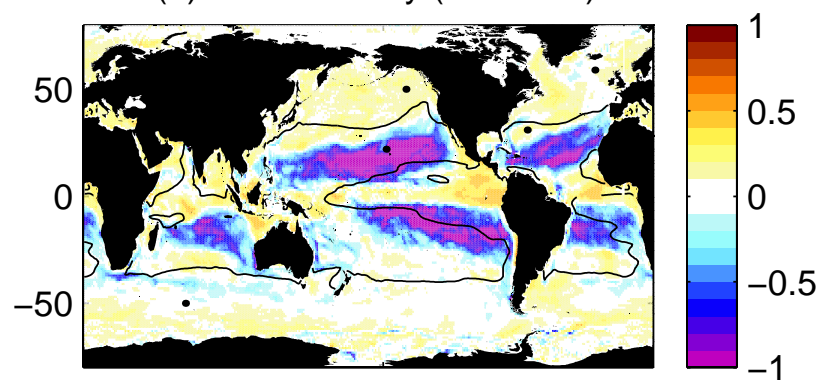

(b) Control-Weekly (UML min)

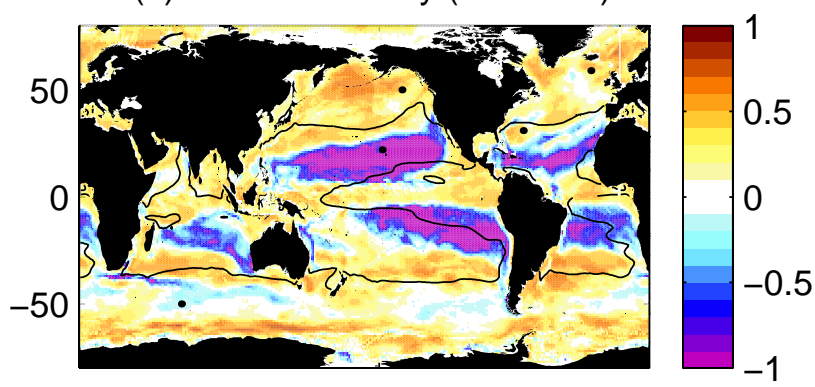

(c) Control-Monthly (UML min)

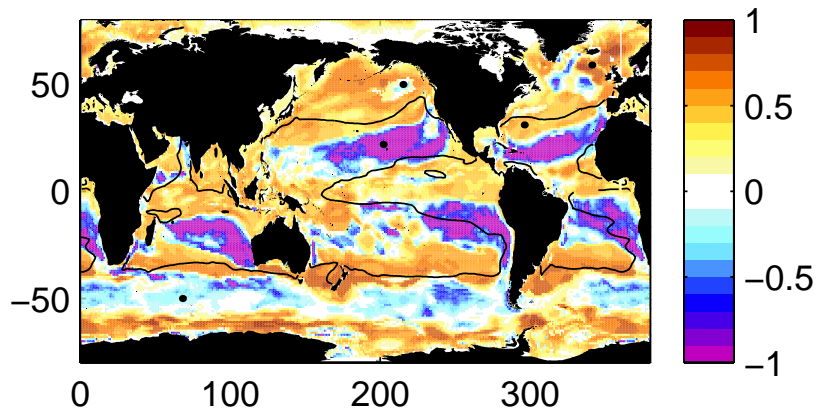

Fig. 5. Differences at each point between the minimum monthly UML depth in the control run and in the runs driven by dailyaveraged (a), weekly-averaged (b) and monthly-averaged (c) forcing, divided by the minimum monthly UML depth in the control run at that point. Differences in the following figures (except Fig. 6b) are also calculated in this way as $\frac{X_{\text {control }}-X_{\text {experiment }}}{X_{\text {control }}}$. Negative values highlight areas where averaging of the forcing fields leads predicted summer-time UMLs being deeper than in the $6 \mathrm{~h}$ run. These areas include equatorward regions of the subtropical gyres, with station HOT being situated in one such area. Regions showing positive values which include the poleward parts of the subtropical gyres as well as moderate and high latitude areas of the Northern hemisphere, show shallower predicted UMLs when the forcing is averaged. Black dots show the locations of the five time series stations discussed in the text and shown on Figs. 2 and 10.

these areas when using monthly forcing is $3-4$ times deeper than in the control run. The reasons for this are not entirely clear to us. We suppose that when weekly,daily or 6-hourly fields are employed, there are occasional periods of weak (a) Contr.R. UML max

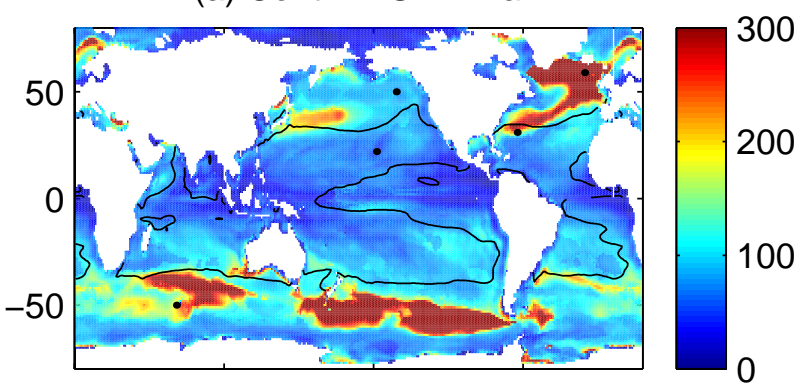

(b) Control-monthly (UML max)

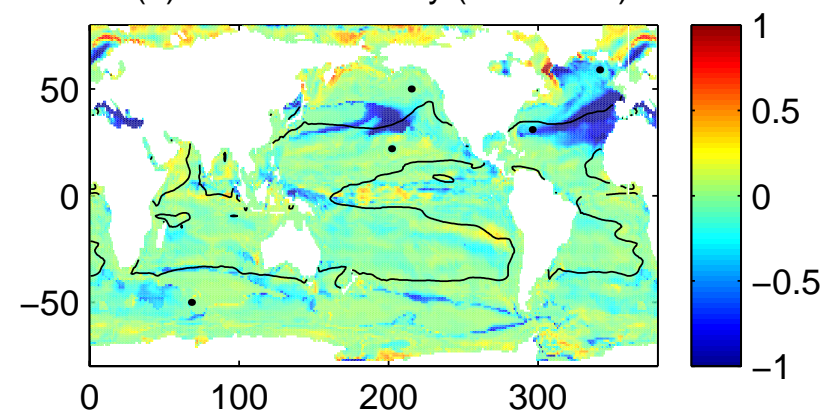

Fig. 6. (a) The maximum monthly averaged daily maximum (nighttime) UML depth, in $\mathrm{m}$. (b) The difference between the maximum monthly averaged daily maximum (night-time) UML depth (a) and the maximum monthly-averaged UML depth in the run driven by monthly-averaged forcing.

mixing. At these times eddy processes parameterized by the Gent and McWilliams bolus transport may operate so as to restratify the "fossil" mixed layers left behind. This additional stratification is suppressed if monthly averaged fields are employed, as the Gent and McWilliams process is not active within the mixed layer itself. Station India, which is located on the periphery of one such area, shows a doubling of the maximum depth of winter mixing under the monthly forcing (Fig. 2d, note the logarithmic scale). The impact of using monthly forcing fields on the maximum depth of the winter mixing does not exceed $20 \%$ in the rest of the ocean, and so is only of relatively minor significance for ecosystem dynamics.

UML variability during the winter is substantially different under the different external forcings (mechanism ii). UML in the $6 \mathrm{~h}$ run exhibits frequent periods of near surface restratification followed by the return of winter convection (Fig. 2). Daily average forcing produces a relative constancy in the depth of the UML, with no periods of restratification between the storms in moderate and high latitudes (e.g. India, KERFIX, Papa, Fig. 2). In low latitudes, however, daily averaged forcing does resolve periods of shallow stratification (see HOT and BATS, Fig. 2). In the weekly and monthly runs, these periods are absent even at low latitudes. 
Table 1. Impact of the variation of the external forcing frequency on the primary production in the subtropical gyres, high and moderate latitudes and equatorial region.

\begin{tabular}{|c|c|c|c|c|}
\hline Area & $\begin{array}{l}\text { Factors limiting } \\
\text { primary production }\end{array}$ & $\begin{array}{l}\text { Features of the UML dy- } \\
\text { namics controlling the fac- } \\
\text { tors limiting pr. production }\end{array}$ & $\begin{array}{l}\text { Impact of the forc- } \\
\text { ing on the UML fea- } \\
\text { tures controlling the } \\
\text { production }\end{array}$ & $\begin{array}{l}\text { Sensitivity of the PP and } \\
\text { NP to the change of the } \\
\text { forcing frequency }\end{array}$ \\
\hline $\begin{array}{l}\text { Central subtrop- } \\
\text { ical gyres }\end{array}$ & $\begin{array}{l}\text { Nutrient availabil- } \\
\text { ity }\end{array}$ & $\begin{array}{l}\text { Maximum depth of winter } \\
\text { mixing (controls amount of } \\
\text { nutrients available for pri- } \\
\text { mary production, mecha- } \\
\text { nism i) }\end{array}$ & $\begin{array}{l}\text { Unaffected by the } \\
\text { change in the fre- } \\
\text { quency of the forcing }\end{array}$ & $\begin{array}{l}\text { Unaffected by the fre- } \\
\text { quency of the forcing }\end{array}$ \\
\hline \multirow[t]{2}{*}{$\begin{array}{l}\text { Periphery of } \\
\text { the subtropical } \\
\text { gyres }\end{array}$} & $\begin{array}{l}\text { Summer: nutrient } \\
\text { limitation }\end{array}$ & $\begin{array}{l}\text { Storm-induced mixing } \\
\text { (increases nutrient supply } \\
\text { mechanism ii) }\end{array}$ & $\begin{array}{l}\text { Resolved in } 6 \mathrm{~h} \text { and } \\
\text { in a lesser degree in } \\
\text { daily forcing }\end{array}$ & $\begin{array}{l}\text { Resolving atmospheric } \\
\text { synoptic events ( } 6 \mathrm{~h} \text { and } \\
\text { daily forcing) substan- } \\
\text { tially increases PP and } \\
\text { NP }\end{array}$ \\
\hline & $\begin{array}{l}\text { Winter: light limi- } \\
\text { tation }\end{array}$ & $\begin{array}{l}\text { Short-term restratification } \\
\text { events (reduce the light } \\
\text { limitation, mechanism iv) }\end{array}$ & $\begin{array}{l}\text { Resolved in } 6 \mathrm{~h} \text { and } \\
\text { in a lesser degree in } \\
\text { daily forcing }\end{array}$ & \\
\hline \multirow[t]{2}{*}{ High latitudes } & $\begin{array}{l}\text { Grazing/light } \\
\text { (Southern Ocean); } \\
\text { Grazing (Pacific); }\end{array}$ & $\begin{array}{l}\text { Short-term winter restrati- } \\
\text { fication events (leads to a } \\
\text { tight coupling between } \mathrm{P} \\
\text { and } \mathrm{Z} \text {, mechanism iv) }\end{array}$ & $\begin{array}{l}\text { Resolved only in } 6 \mathrm{~h} \\
\text { forcing }\end{array}$ & $\begin{array}{lr}\text { Resolving } & \text { the diur- } \\
\text { nal cycle } & \text { substantially } \\
\text { decreases } & \text { primary } \\
\text { production } & \end{array}$ \\
\hline & $\begin{array}{l}\text { Grazing/nutrients } \\
\text { (North Atlantic) }\end{array}$ & $\begin{array}{l}\text { Average winter mixing } \\
\text { depth (controls zooplank- } \\
\text { ton survival, mechanism } \\
\text { iii) }\end{array}$ & $\begin{array}{l}\text { Unrealistically in- } \\
\text { creased in the } \\
\text { monthly run in } \\
\text { some locations; the } \\
\text { same in } 6 \mathrm{~h} \text {, daily and } \\
\text { weekly runs }\end{array}$ & \\
\hline Equatorial areas & Light/Grazing & $\begin{array}{l}\text { Diurnal cycle of the UML } \\
\text { and storm-induced mixing } \\
\text { produce stronger light lim- } \\
\text { itation (mechanism v) as } \\
\text { well as increased grazing } \\
\text { pressure }\end{array}$ & $\begin{array}{l}\text { Resolved by } 6 \mathrm{~h} \text { forc- } \\
\text { ing }\end{array}$ & $\begin{array}{l}\text { Resolving the diurnal } \\
\text { cycle substantially de- } \\
\text { crease primary and new } \\
\text { production }\end{array}$ \\
\hline
\end{tabular}

\subsection{Primary and new production}

In this section we examine the impact of the frequency of external forcing, as manifested in UML variability, on primary and new production. The impacts of the different forcings vary markedly between oligotrophic areas of the subtropical gyres, high and moderate latitudes, and equatorial areas (Fig. 7, Table 1). A mean annual nitrate concentration of $1 \mathrm{mmol} \mathrm{m}^{-3}$, as shown in Figs. 5, 4, 7, 9, was chosen as a means of defining the boundaries between these different regions. The resulting mean annual integrated primary and new production for these areas is shown in Fig. 8. Analysis was restricted to areas free from seasonal ice cover (between $60^{\circ} \mathrm{S}$ and $70^{\circ} \mathrm{N}$ ) since the variation of the ice boundary with that of the external forcing frequency is significant and beyond the scope of this paper. The primary production at five JGOFS locations for each of the model runs is presented in Fig. 10. As shown in Fig. 8, the major change in the global primary and new productions occurs when the frequency of the external forcing increases from daily to $6 \mathrm{~h}$. In this case global (excluding zones affected by the seasonal ice cover) primary production declines by about $25 \%$ while the new production declines by about $10 \%$. Equatorial and high latitude areas contribute most toward the decrease, while oligotrophic gyres show a small increase in both new and total primary production. Decreasing the forcing frequency from daily to weekly and then monthly impacts on the production to a much lesser degree with the effect not exceeding 5-7\%. Regional variations can however be quite high (see the discussion below).

\subsubsection{High and moderate latitudes}

The area of high and moderate latitudes includes three substantially different sub-areas within the model: the subarctic Pacific, northern North Atlantic and the Southern Ocean. The subarctic Pacific is characterised by relatively shallow winter mixing compared with that of the same latitudes of the North Atlantic and Southern Ocean. This lack of deep winter convection allows the modelled zooplankton populations to survive in numbers throughout the winter and exert significant grazing control over the primary production. Station 
a) Control-Daily (pr.prod)

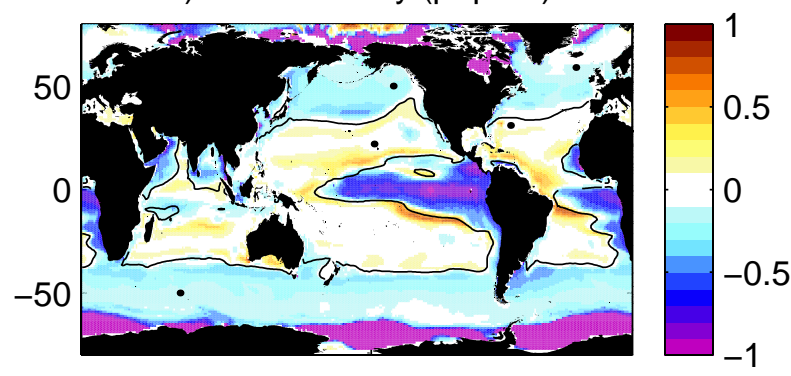

b) Control-Weekly (pr. prod)

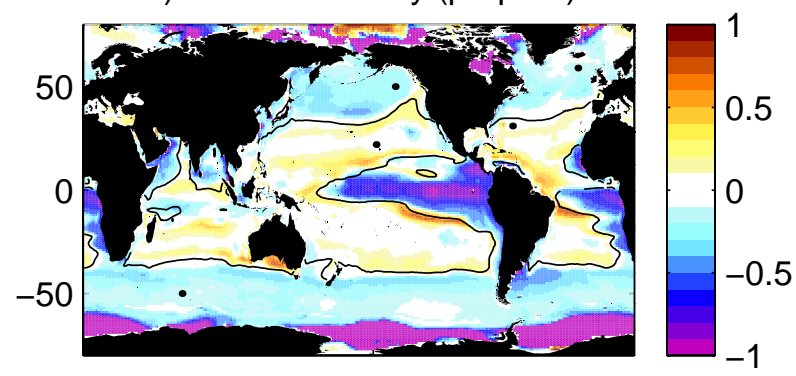

c) Control-Monthly (pr. prod)

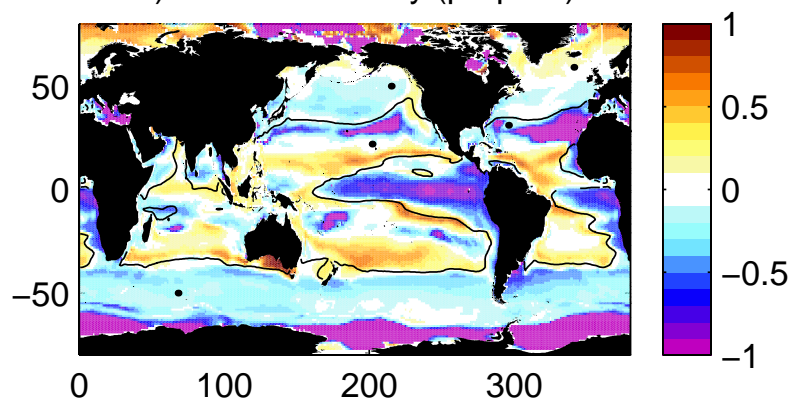

d) Control-Daily (new prod)

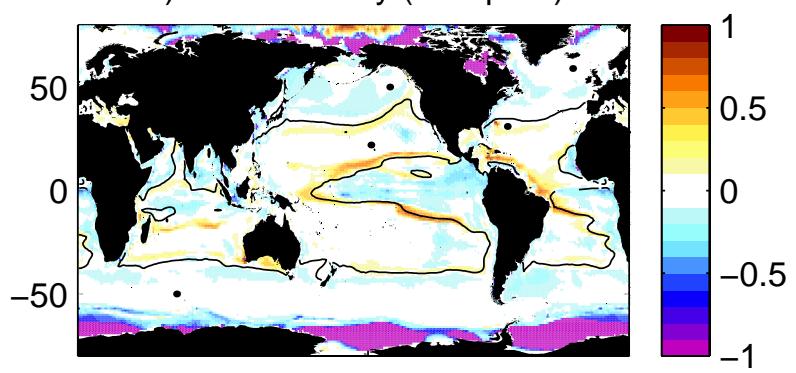

e) Control-Weekly (new prod)

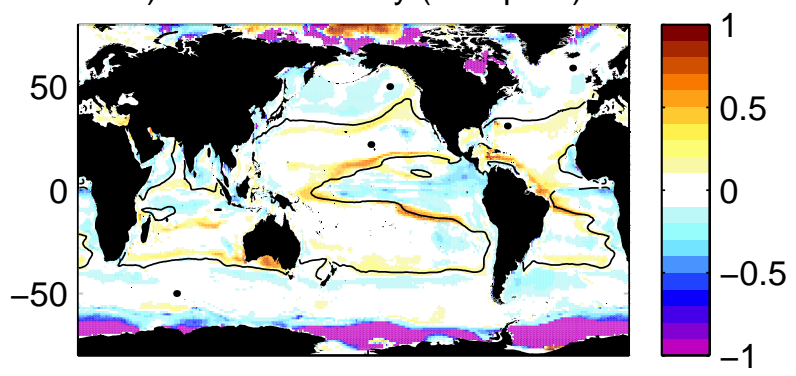

f) Control-Monthly (new prod)

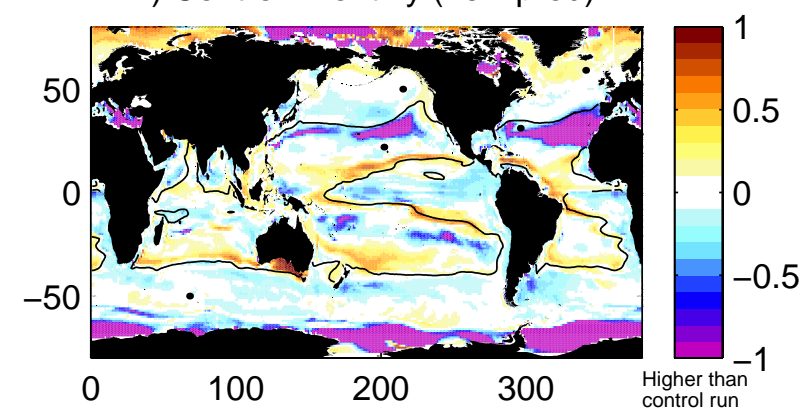

Fig. 7. Deviation of the mean annual primary production in the control run (see Fig. 5 for additional explanation) from the daily forcing run (a), weekly forcing run (b), monthly forcing run (c); deviation of the mean annual new production in the control run from the daily forcing run (d), weekly forcing run (e), monthly forcing run (f). Black dots show the locations of the five time series stations discussed in the text and shown on Figs. 2 and 10.
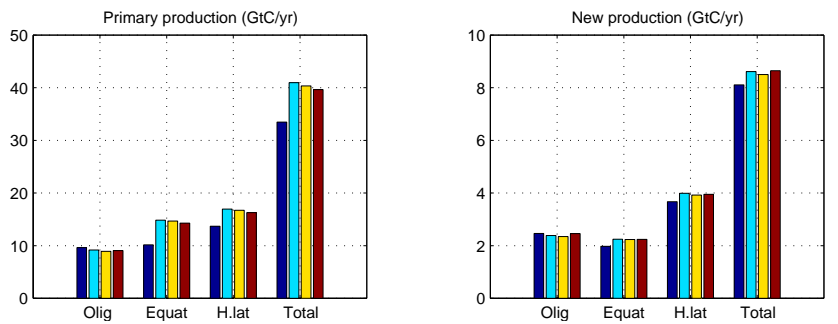

Fig. 8. Mean annual primary (a) and new (b) production $\left(\mathrm{GtC} \mathrm{yr}^{-1}\right)$ integrated over the equatorial, oligotrophic and high latitude areas (see text) and the global ocean for the $6 \mathrm{~h}$ (dark blue), daily (light blue), weekly (yellow) and monthly (red) forcing runs.
Papa (Figs. 2c, 10c) provides a good example of ecosystem dynamics in the subarctic Pacific (PC06).

In contrast, the high and moderate latitudes of the North Atlantic exhibit a pronounced spring bloom initiated by stable stratification after deep winter convection. At the highest latitudes this bloom is predicted to subside before nutrients are depleted, a result of top-down control by zooplankton grazers. Station India (PC06) is typical of this domain (Figs. 2d, 10d). Further south, the bloom is terminated after nutrient exhaustion, its magnitude depending on the depth of the preceding winter convection. Predicted ecosystem dynamics at Bermuda (Figs. 2e, 10e), which is situated on the periphery of the oligotrophic gyre, show features of both the oligotrophic and moderate latitude regimes due to its relatively deep (200-350 m) winter convection. 
Primary production in the Southern Ocean is limited in the model by both grazing and light. In a similar fashion to the high latitudes of the Pacific Ocean, this area does not experience deep winter convection, a situation leading to grazing control over phytoplankton growth in spring. Light limitation of primary production is also prevalent in summer due to the extremely deep UML that occurs at that time of year (PC06). Station Kerfix (PC06) provides a good example of ecosystem dynamics in the Southern Ocean (Figs. 2a, 10a).

Lowest rates of new and total primary production were predicted when using the $6 \mathrm{~h}$ external forcing in these areas (Figs. 7, 8). Using the higher frequency external forcing reduces the predicted magnitude of the spring bloom in the North Atlantic, while in the Pacific and Southern ocean the primary production is reduced throughout the whole summer period. The cause of this reduction is related to shortterm spring restratification events (mechanism iv) which occur when the system oscillates between deep winter convection and a shallow stable UML. During such periods, both the phytoplankton and zooplankton populations develop quickly together such that when conditions are ideal for phytoplankton to bloom, the zooplankton population is sufficiently large to exert top-down control and thereby prevent any bloom from occurring. Such periods do not occur when using the monthly and weekly forcings, while in the daily run they are much less frequent than in the run with the $6 \mathrm{~h}$ external forcing.

In order to examine the strength of grazing in controlling primary production (mechanisms iii and iv) we chose as a proxy the surface mean annual zooplankton to phytoplankton ratio (Fig. 9). This ratio illustrates the significant increase in grazing pressure at high latitudes that is predicted when the diurnal cycle is resolved (Fig. 9a), most significantly in the subarctic Pacific, and to a lesser degree in the Southern Ocean and the northern North Atlantic. While the largest changes are obtained by resolving the diurnal cycle, the difference between the production predicted under daily and weekly forcings is negligible. The depth of winter convection remains the same when the forcing frequency decreases from $6 \mathrm{~h}$ to weekly, thus rendering mechanism (iii), the effect of grazing pressure, inactive. However, the use of monthly forcing significantly deepens the predicted winter convection in the northern North Atlantic (Fig. 2d, India, and 2e, BATS, see also Fig. 6b) and leads to much larger blooms than in any of the other runs, the reduction in grazing pressure once again being of importance. The importance of resolving the diurnal cycle suggests that mechanism iv (short-term spring restratification) plays the dominant role in controlling primary production and that it is necessary to resolve the diurnal cycle if the coupling between phytoplankton and zooplankton is to be modelled adequately.

The use of $6 \mathrm{~h}$ forcing, and its impact on the coupling between phytoplankton and zooplankton, has a much greater effect on total primary production than on the new production (cf. Figs $7 \mathrm{a}-\mathrm{c}$ and $7 \mathrm{~d}-\mathrm{f}$ ). Resolving the diurnal cycle in a) Control-Daily (Z/P)

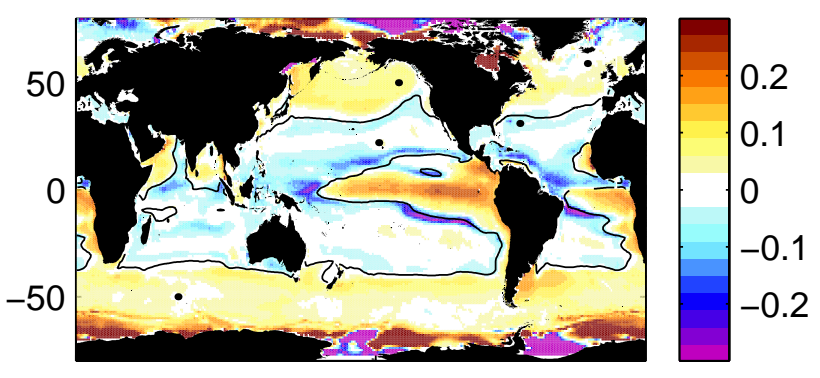

b) Control-Weekly (Z/P)

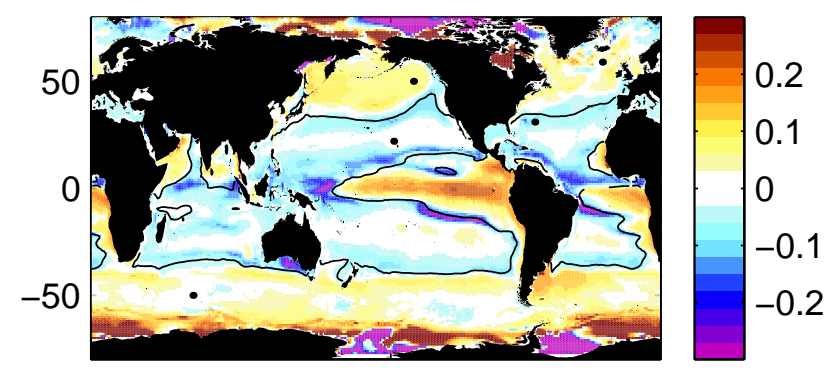

c) Control-Monthly (Z/P)

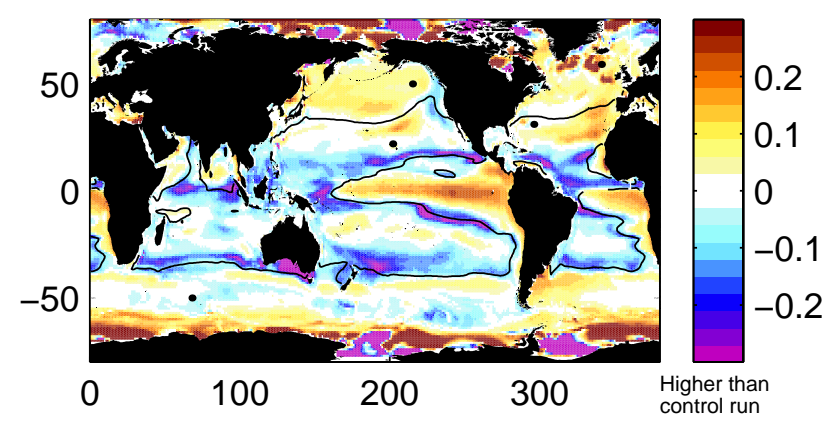

Fig. 9. Deviation of the surface phyto- to zooplankton ratio in the control run (see Fig. 5 for additional explanation) from the daily forcing run (a), weekly forcing run (b), monthly forcing run (c). Black dots show the locations of the five time series stations discussed in the text and shown on Figs. 2 and 10.

the Southern Ocean, for example, reduces primary production by $30-40 \%$ while new production remains almost unaffected. This difference is because the zooplankton grazing pressure affects the amount regenerated rather than new production.

\subsubsection{Subtropical gyres}

Deep winter mixing is absent in the central areas of the subtropical oligotrophic gyres and so primary production is limited primarily by nutrient availability. Station HOT provides a good example of ecosystem dynamics in the oligotrophic gyres (PC06). The absolute maximum depth of the UML 
(a) KERFIX
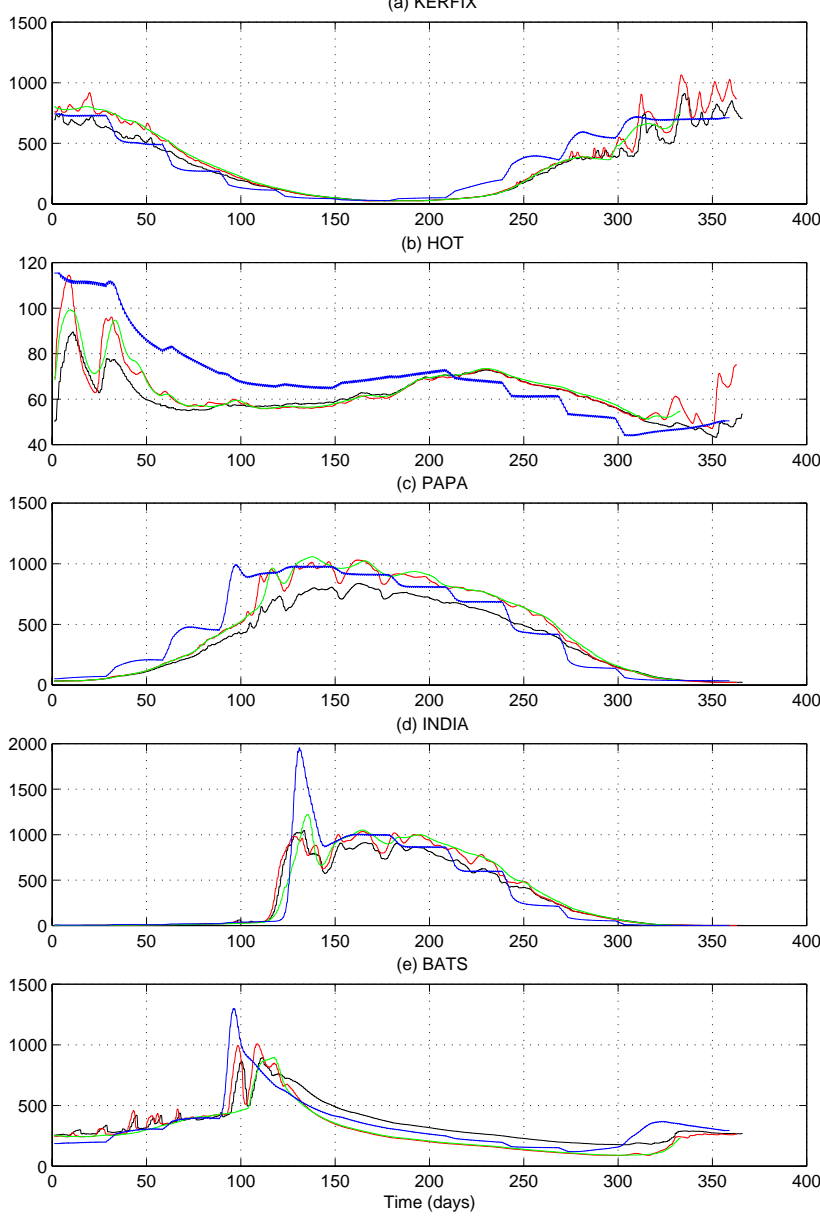

Fig. 10. Photic zone integrated primary production $\left(\mathrm{mgC} \mathrm{m}^{-2} \mathrm{~d}^{-1}\right)$ for the year 1992 at KERFIX (a), HOT (b), Papa (c), India (d), BATS (e) in the control run (black), daily (red), weekly (green) and monthly (blue) forcing runs.

is the factor determining the nutrient supply (mechanism i) in these areas and hence also annual primary and new production. As was shown above, this depth is the same in the $6 \mathrm{~h}$, daily and weekly run (Fig. 2b, station HOT), and so the predicted annual primary and new production remain almost unaffected by the change in the frequency of the forcing.

On an intra-annual time scale, winter productivity peaks in the $6 \mathrm{~h}$ run are lower than in the daily forcing run (Fig. 10b). These peaks occur during periods of calm weather between storms, which are generally persistent for a few days in the daily forcing run, while being interrupted by the deeper night-time UML in the $6 \mathrm{~h}$ run (Fig. $2 \mathrm{~b}$ ). Since the nutrient supply from below is the same in $6 \mathrm{~h}$ and daily runs (mechanism ii), resolving the diurnal cycle reduces the amplitude of blooms of phytoplankton because of the stronger impact of light limitation (mechanism v). In the weekly run, winter restratification periods are almost absent. The system dur- ing the winter is shifted towards light limitation more than in $6 \mathrm{~h}$ and daily runs and the magnitude of the winter blooms is somewhat different. This effect is not however systematic and does not affect annual ecosystem characteristics controlled by the depth of maximum winter mixing. Primary production in the monthly run shows the single winter maximum and summer minimum without any smaller-scale oscillations.

Towards the periphery of the gyres, where winter mixing can reach significant depths, primary production is limited by nutrient availability only in summer. Light conditions play the dominant role in winter, although primary production during this season remains high. In these areas, an increase in frequency of the external forcing increases both primary and new production by up to a factor of two (Fig. 7). Two mechanisms are responsible for this enhanced productivity. The first involves the existence of short-term periods of shallow stratification during calm weather in winter. During such periods, which last from one to two days and are well resolved in the $6 \mathrm{~h}$ and daily runs, light conditions are ameliorated and significant production occurs. The effect is usually more pronounced in the daily run because such shallowings are not predicted to be interrupted by deepening of the mixed layer during the night. UML dynamics of this type are seen in the model at BATS (Figs. 2e and 10e), although responses to forcings at this station are more typical of those of the moderate latitudes, as is discussed below. The second mechanism involves the prediction of deeper storm-induced mixing in summer in the $6 \mathrm{~h}$ run (Figs. 2e and 10e), which increases the nutrient supply and therefore tends to increase productivity. Unlike in the centres of the gyres, predicted nutrient concentrations below the UML in summer are still significant. Nutrient supply from below is then enhanced by night-time deepenings and better resolved storm-induced mixing in the $6 \mathrm{~h}$ run.

The two mechanisms described above do not however apply to the monthly forcing which generates unrealistically deep mixing over some areas of the gyres, especially in the northern hemisphere, where winter mixing can deepen by a factor of 3-4 (Fig. 6b). Such a deepening significantly increases nutrient supply to the gyre and doubles primary production in the areas where limitation by nutrients substantially exceeds that by light (Fig. 7c, f). On the other hand, production in the areas which are more severely limited by light, such as southern parts of the southern gyres, declines by a factor of two, so that total production in the subtropical gyres remains the same (Fig. 8).

\subsubsection{Areas affected by equatorial and coastal upwelling}

In the equatorial areas, monthly, weekly and daily averaged forcing produce very similar results. Resolution of the diurnal cycle did however decrease predicted primary production by about $30-50 \%$ (Fig. 7) by increasing the averaged UML depth (mechanism v), impacting on the light limitation of 
phytoplankton growth (Fig. 5a-c) and also increasing grazing pressure (Fig. 9a). The impact of the $6 \mathrm{~h}$ forcing on new production is much smaller and does not exceed $20 \%$. This effect is minimal because equatorial upwelling, the main source of new nutrients in the area, remains mostly unaffected by variations in wind frequency.

The total predicted new and primary production of the equatorial area in the $6 \mathrm{~h}$ run is considerable, being around 2 and $10 \mathrm{Gt} \mathrm{Cyr}^{-1}$ for each area respectively (Fig. 8). These values increase to 2.3 and $15 \mathrm{GtC} \mathrm{yr}^{-1}$ in the run with daily average forcings. The significance of these changes are not just local, but extend to have a major impact on the global predictions of primary and new production.

\section{Discussion}

The sensitivity of ecosystem dynamics to the high frequency variations in external forcing, with resulting consequences for variability in the UML, was investigated using a global ecosystem model. The motivation for the work was the fact that global or basin-scale models often use simplistic representations of the UML and/or low frequency external forcing and are therefore unable to capture short-term variability in the UML. The model of Aumont et al. (2003), for example, has no explicit treatment of the UML, using instead a photic zone of $100 \mathrm{~m}$ that undergoes vertical mixing with neighbouring $50 \mathrm{~m}$ deep grid cells. Likewise, the use of long time steps, a common feature of global models subjected to lengthy runs, ignores short term variations in UML. The model of Six and Maier-Reimer (1996), for example, uses a time step of one month. In similar fashion, the bulk Krauss-Turner mixed layer scheme employed by Palmer and Totterdell (2001) employs monthly mean external forcing, with further difficulties arising from the homogenising of state variables throughout even the deepest UMLs.

In our study we compared four runs of a global GCM driven by monthly, weekly, daily and $6 \mathrm{~h}$ external forcing. Results showed that resolving diurnal variation in forcing had impacts on predicted global patterns of primary and new production extending far beyond this timescale. Globally integrated values of primary and new production were significantly altered when using high frequency forcing. An intriguing discovery was that episodic events of very calm, rather than very stormy, weather had the greatest impact on predicted primary production, and that furthermore the events during the winter months were of greatest significance.

It should be emphasised that the difference between the daily and $6 \mathrm{~h}$ external forcing is not only in resolving the diurnal cycle of the forcing and consequently of the UML with deepening during the night and shallowing during the day. In addition, the $6 \mathrm{~h}$ forcing provides a much improved resolution of extreme values of the wind stress during storms as well as a better representation of occasional very calm weather, both of which are usually persistent for a day or two. The time scale of these events is too short to be properly resolved by using daily averaged forcing.

To what extent, then, were predicted new and total primary production improved when using $6 \mathrm{~h}$ forcing? One problem area for modellers has always been the oligotrophic gyres in which primary production tends to be severely underestimated in both global and basin-scale models (e.g. Sarmiento et al., 1993; Oschlies et al., 2000). Although predicted primary production in the centre of the oligotrophic gyres was unaffected by the increase in the frequency of the external forcing, and still lower than observed, the peripheries of the gyres showed a significant increase in productivity locally reaching a factor of two when the diurnal cycle was resolved. Two mechanisms are responsible for this increase. The first, affecting mostly regenerated production, is associated with short-term periods of shallow stable stratification during the winter when significant production can occur due to reduced limitation by light. The second mechanism, mostly affecting new production, is associated with storm-induced mixing during spring and summer, which increases vertical nutrient supply. In order to adequately describe the impact of these mechanisms on primary production, a model of atmospheric forcing should resolve not only synoptic atmospheric events but also the diurnal cycle of the forcing fields resulting in the diurnal UML variability which enhances the effect of both of the above mentioned mechanisms.

Another problem area for GCM modellers has been overestimation of primary production in equatorial areas (Oschlies et al., 2000). Results here show that high frequency external forcing may significantly improve the performance of global models in these areas, providing a much deeper predicted UML, and at least partly overcome the problem of overestimated primary production. This overestimation is usually attributed to overestimation in the intensity of upwelling (Oschlies et al., 2000). In fact, the band of high production at the equator can be subdivided into two areas characterised by different physical regimes, but leading to similar ecosystem responses (PC06). One is the equatorial upwelling area with a shallow stable UML, which is surrounded by a second area of equatorial currents with a deeper UML than in the adjacent oligotrophic gyres. This second area therefore has a greater potential for light limitation to suppress primary production. It is therefore important to resolve the significant storm activity in this area, as well as the diurnal cycle of the UML layer, both of which contribute towards stronger light limitation of primary production. Resolving the diurnal cycle by using the $6 \mathrm{~h}$ external forcing caused a decrease of $30 \%$ in predicted primary production of the total equatorial area, the effect being locally as much as factor of five.

In the high-nutrient low-chlorophyll Southern Ocean and subarctic Pacific, the use of $6 \mathrm{~h}$ forcing gives rise to relatively tight coupling between phytoplankton and herbivorous zooplankton. The result is relatively low primary production and low seasonality of the Chl-a, showing better agreement 
with data compared to the runs using other forcings. Short bursts of relatively calm weather during the winter create mini-blooms of phytoplankton and zooplankton in these areas. These bursts serve to sustain the zooplankton population in the model, which is then sufficiently well developed to suppress the development of phytoplankton blooms, the grazing control of productivity extending into the summer. Increasing the frequency of external forcing from $6 \mathrm{~h}$ to $24 \mathrm{~h}$ led to a decline in predicted global primary production (excluding areas affected by seasonal ice cover) from 41 to $33 \mathrm{Gt} \mathrm{C} \mathrm{yr}^{-1}$. The impact of this increase in forcing period on new production is however much smaller being $0.5 \mathrm{Gt} \mathrm{C} \mathrm{yr}^{-1}$ which is only about $10 \%$ of the total annual value. This effect is relatively small because most of the mechanisms that are sensitive to high frequency forcing affect zooplankton grazing pressure which impacts mainly on regenerated rather than new production.

In spite of the generally good agreement with observations, our model has significant limitations with respect to both the ocean dynamics and ecosystem structure. The $1^{\circ}$ resolution means that shelf areas are not represented, and areas affected by seasonal ice cover are only poorly resolved. Mesoscale motion, with its tendency to enhance the horizontal and vertical transports of nutrients, is nonexistent in the model. We can speculate that an increase in resolution will give further improvement in the model performance in the centre of the oligotrophic gyres where the primary production still remains underestimated. The increase of the nutrient supply on the peripheries of the gyres achieved by the higher forcing frequencies can lead to significant intensification of the lateral eddy transport of nutrients towards the centre of the gyres in eddy-resolving models. This point serves only to strengthen the rationale for the need to pay attention to realistically formulating physics in GCMs if reliable predictions of biophysical interactions are to be made.

The introduction of additional factors limiting primary production was needed in order to better describe regionally important factors such as micronutrient limitation in the Southern Ocean and nitrogen fixation in the oligotrophic gyres. Nevertheless, in spite of the effect of these shortcomings on the analysis above, the impact of high frequency forcing on the mechanisms influencing primary production (Fig. 1) has been unequivocally demonstrated. Much of the current emphasis on future directions in global biogeochemical modelling is directed towards increasing complexity in the ecosystems models used (e.g. LeQuere, 2005), although it is by no means clear whether the resulting parameterizations are sufficiently robust to perform in, for example, climate predictions (Anderson, 2005). The results presented here demonstrate the importance of increasing physical complexity in order for numerical models to accurately capture climate change impacts and subsequent biotic feedbacks. Accurate representation of physical processes is necessary before one can hope to achieve realism in predicted biogeochemical fields and their response to climatic forcing.
Of course the biological parameterizations are important too. For example, our results show that the grazing control of primary production is sensitive to variations in the external forcing. Physics and biology alike require consideration if biophysical interactions are to be realistically captured when modelling biogeochemistry in GCMs.

\section{Conclusions}

The use of $6 \mathrm{~h}$, daily, weekly and monthly forcing of atmospheric fields resulted in dramatically different predictions of plankton productivity in a global 3-D coupled physicalbiogeochemical model. Resolving the diurnal cycle of atmospheric variability using of $6 \mathrm{~h}$ forcing, and hence also diurnal variability in UML depth, produced the largest difference, reducing predicted global primary and new production by $25 \%$ and $10 \%$ respectively relative to that predicted with lower frequency forcing. This variation varied regionally, being a $30 \%$ reduction in equatorial areas, $25 \%$ at moderate and high latitudes and a $10 \%$ increase in the peripheries of the oligotrophic gyres. Predicted primary and new production in the centres of the oligotrophic gyres remains unaffected by the frequency of the external forcing because the maximum depth of the UML throughout the year was independent of the frequency of forcing and the depth of the nitracline is deeper than the maximum UML depth. In these areas, severely limited by nutrient availability, this depth is the main factor determining mean annual primary and new production.

Two mechanisms associated with short term episodic mixing are of greatest importance in contributing to the differences in primary production predicted for different forcings. The first is restratification events during periods of calm weather between storms in winter, which are well resolved under the $6 \mathrm{~h}$ forcing. The use of daily forcing also resolved these events, but to a lesser degree. Significant growth of phytoplankton occurs during these periods of restratification, thus enhancing the predicted annual production. Moreover, these events tend to enhance coupling between phytoplankton and their herbivorous grazers, preventing the occurrence of blooms at high latitudes and thus reducing annual primary and new production in these areas. Second, the use of $6 \mathrm{~h}$ forcing permits a good resolution of maximum wind speed during storm events, thus generating deeper mixing than in runs with lower frequency forcing.

Resolution of the diurnal cycle of the UML, with its deepening during the night and shallowing during the day, also affects averaged UML depth and so significantly influences productivity. It is the UML depth averaged over the summer period that determines the level of ligh limitation of annual primary production. Average winter mixing depth influences the extent to which zooplankton can survive through the winter and hence exert grazing pressure on the spring phytoplankton bloom. The use of monthly forcing gave rise 
to various unrealistic features in both the physical and biological variables of the model. Unrealistically deep winter convection was predicted in the moderate latitudes of the North Atlantic and North Pacific oceans, causing a dramatic increase in predicted primary and new production. In addition, model runs employing either monthly or weekly forcing fields are missing important mechanisms that control primary and new production, namely episodic storm-induced mixing and short-term winter time near-surface restratification during the calm weather, and cannot therefore be recommended for use in predicting, for example, the response of the marine biota to climate change. Although daily forcing gives a relatively good description of some mechanisms involved in controlling primary production such as the impact of storms, it smoothes out the diurnal cycle of the UML which has a profound implications regarding the light limitation of the productivity. Thus resolving the diurnal cycle in the equatorial areas reduced primary production by $30 \%$ due to the increase of limitation by light.

By resolving the diurnal cycle in a 3-D coupled physical and biological model, performance was significantly improved with respect to several common problems: underestimated primary production in the oligotrophic gyres; overestimated primary production in the Southern Ocean; overestimated magnitude of the spring bloom in the subarctic Pacific Ocean, and overestimated primary production in equatorial areas. The result of using $6 \mathrm{~h}$ forcing on predicted ecosystem dynamics was profound, the effects persisting far beyond the hourly timescale, and having major consequences for predicted global and new production on an annual basis.

Acknowledgements. The work had been supported by the Natural Environment Research Council core strategic programs BICEP (Biophysical Interactions and Controls on Export Production) and LSTOC (Large Scale Long Term Ocean Circulation).

Edited by: V. Garcon

\section{References}

Anderson, T. R.: Plankton functional type modelling: running before we can walk?, J. Plankton Research, 27, 1073-1081, 2005.

Aumont, O., Maier-Reimer, E., Blain, S., and Monfray, P.: An ecosystem model of the global ocean including $\mathrm{Fe}, \mathrm{Si}$, P colimitations, Global Biogeochem. Cy., 17, 29.1-29.15, doi:10.1029/2001GB001745, 2003.

Brainerd, K. E. and Gregg, M. C. : Surface mixed and mixing layer depths, Deep-Sea Research, 42, 1521-1543, 1996.

Conte, M. H., Dickey, T. D., Weber, J. C., Johnson, R. J., and Knap, A. H.: Transient physical forcing of pulsed export of bioreactive organic material to the deep Sargasso Sea, Deep Sea Research I, 50, 1157-1187, 2003.

Dickey, T., Zedler, S., Frye, D., Jannasch, H., Manov, D., Sigurdson, D., McNeil, J. D., Dobeck, L., Yu, X., Gilbo, T. Y., Bravo, C., Doney, S. C., Siegel, D. A., and Nelson, N.: Physical and biogeochemical variability from hours to years at the Bermuda
Testbed Mooring: June 1994-March 1998, Deep Sea Research, II, 48, 2105-2140, 2001.

Fasham, M. J. R., Ducklow, H. W., and McKelvie, S. M.: A nitrogen-based model of plankton dynamics in the oceanic mixed layer, J. Mar. Res., 48, 591-639, 1990.

Fasham, M. J. R. and Evans, G. T.: The use of optimisation techniques to model marine ecosystem dynamics at the JGOFS station at $47^{\circ}$ N $20^{\circ}$ W, Phil. Trans. Roy. Soc. Lond., B 348, 206209, 1995.

Follows, M. and Dutkiewicz, S.: Meteorological modulation of the North Atlantic spring bloom, Deep Sea Res., Part II, 49, 321344, 2002.

Karl, D. M., Dore, D. E., Lucas R., Michaels, A. F., Bates, N. R., and Knap, A.: Building the long-term picture: the US JGOFS time-series Programs, Oceanogr., 14, 6-17, 2001.

Kawamiya, M. and Oschlies, A.: Simulated impact of intraseasonal variations in surface heat and momentum fluxes on the pelagic ecosystem of the Arabian Sea, J. Geophys. Res., 109, C03016, doi:10.1029/2003JC002107, 2004.

Large, W. G., Danabasoglu, G., and Doney, S. C.: Sensitivity to Surface Forcing and Boundary Layer Mixing in a Global Ocean Model: Annual-Mean Climatology, J. Phys. Oceanogr., 27, 2418-2446, 1997.

LeQuere, C., Harrison, S. P., Prentice, I. C., et al.: Ecosystem dynamics based on plankton functional types for global ocean biogeochemistry models, Global Change Biology, 11, 2016-2040, 2005.

McCreary, J. P., Kohler, K. E., Hood, R. R., Smith, S., Kindle, J., Fischer, A., and Weller, R. A.: Influences of diurnal and intraseasonal forcing on mixed-layer and biological variability in the central Arabian Sea, J. Geophys. Res., 106, 7139-7155, 2001.

Oschlies, A.: Equatorial nutrient trapping in biogeochemical ocean models, the role of advection numerics, Global Biogeochem. Cycles, 14, 655-667, 2000.

Oschlies, A., Koeve, W., and Garçon, V.: An eddy-permitting coupled physical-biological model of the North Atlantic 2. Ecosystem dynamics and comparison with satellite and JGOFS local studies data, Global Biogeochem. Cy., 14, 499-523, 2000.

Palmer, J. R. and Totterdell, I. J.: Production and export in a global ecosystem model, Deep-Sea Research I, 48, 1169-1198, 2001.

Popova, E. E., Coward, A. C., Nurser, G. A., DeCuevas, B., and Anderson, T. R.: Mechanisms controlling primary and new production in a global ecosystem model - Part I: Validation of the biological simulation, Ocean Sci., 2, 249-266, 2006, http://www.ocean-sci.net/2/249/2006/.

Sarmiento, J. L., Slater, R. D., Fasham, M. J. R., Ducklow, H. W., Toggweiler, J. R., and Evans, G. T.: A seasonal threedimensional ecosystem model of nitrogen cycling in the North Atlantic euphotic zone, Global Biogeochem. Cycles, 7, 417-450, 1993.

Six, K. D. and Maier-Reimer, E.: Effects of plankton dynamics on seasonal carbon fluxes in an ocean general circulation model, Global Biogeochem. Cy., 10, 559-583, 1996.

Waniek, J.: The role of physical forcing in initiation of spring blooms in the Northeast Atlantic, J. Mar. Syst., 39, 57-82, 2003. 